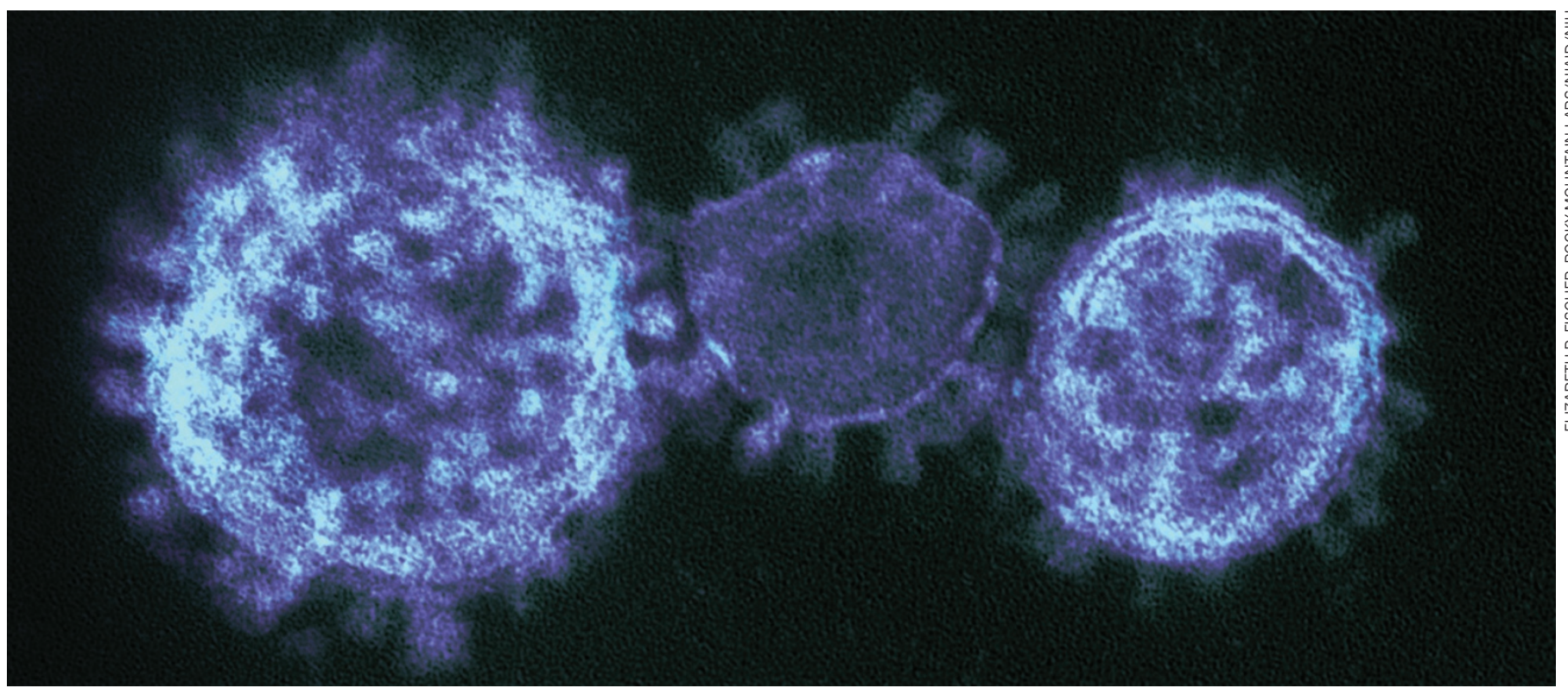

A new coronavirus found in the Middle East is one of a family of viruses named after the corona-like appearance of their surface spikes.

VIROLOGY

\title{
Clusters of coronavirus cases put scientists on alert
}

\section{Surveillance ramped up after novel virus is identified in three Middle Eastern countries.}

\section{BY DECLAN BUTLER}

$\mathrm{I}$ $s$ the coronavirus that has appeared in the Middle East a simmering threat to global 1 public health or a viral footnote that will end up being of interest only to academics? That is the key question that researchers and public-health officials are now struggling to resolve. Two unsettling developments have fed their concerns: fresh hints that the virus might show at least limited spread from person to person, and signs that it has extended its geographical range.

Last week, the World Health Organization (WHO) urged that surveillance for the virus, called human betacoronavirus 2c EMC/2012, should be extended to all countries worldwide, with a special focus on all clusters of severe pneumonia, particularly in health workers. Epidemiologists say that the nebulous threat requires close monitoring, by investigating and controlling any new clusters of human cases that could signal that the virus has adapted to spread between people more easily.

The coronavirus, first reported on 20 September, causes severe pneumonia and often kidney failure. In the nine cases confirmed so far, it has had a death rate of more than $50 \%$. "It's an extremely serious disease; it's very much in the category of H5N1 [avian influenza]," says David Heymann, chairman of the UK Health Protection Agency and former head of the communicable-diseases programme at the WHO during the 2003 SARS epidemic, caused by a different coronavirus. Yet this latest coronavirus is still limited to the Middle East and shows no sign of spreading easily between people, Heymann emphasizes.

\section{In late November,}

“It's an extremely however, the WHO serious disease; it's very much in the category of H5N1." reported a household cluster of four cases in Saudi Arabia, in which two people died. Retrospective tests looking for the coronavirus in samples from a cluster of 11 people who were admitted with serious respiratory symptoms to a hospital in Jordan in April have revealed the virus in another two fatal cases. This pushes back the first known date of its emergence by several months and marks the first evidence for infection outside Saudi Arabia and Qatar.

Although independent infections from the same animal or environmental source might explain these outbreaks, such clusters always raise the possibility of transmission between humans. Because the disease did not spread

any further, however, person-to-person transmission of the virus - if it occurred at all - would have had to have been through close contact. Still, the extension of the disease to Jordan, and the identification of these earlier cases, marks a significant epidemiological development and suggests that infections may have gone undetected in other countries.

What is needed now, says Heymann, is "good old shoe-leather epidemiology; that's what worked in SARS". Epidemiologists need to talk to the families and neighbours of any infected people; try to track down everyone who has come into contact with them to look for symptoms and test for the virus; and isolate infected people to try to stop any spread.

Researchers including Christian Drosten, director of the Institute of Virology at the University of Bonn Medical Centre in Germany, have moved quickly to develop diagnostic tests to determine whether people or samples are infected with the coronavirus ${ }^{1,2}$. These tests are now being rolled out by many national health authorities, and Drosten says that a survey in

$\rightarrow$ NATURE.COM

For a coronavirus case timeline, see: go.nature.com/xtr5wj Europe is showing a particularly quick response.

Teams from the WHO and the US Centers for Disease Control and 
Prevention in Atlanta, Georgia, have been helping countries in the Middle East to boost surveillance. During the annual hajj religious pilgrimage in Saudi Arabia in late October, when millions of people visited the country before returning home - a potential recipe for global virus spread - both Saudi Arabia and return countries were on high alert.

Beyond immediate surveillance efforts, increased monitoring for coronavirus antibodies in the wider population should help to pin down the true death rate. The current high death rate would fall, for example, if many people in the vicinity of cases turn out to have antibodies to the virus but have not developed serious disease.

Meanwhile, laboratory studies are shedding light on the virus itself. This week, a team including Drosten has shown that this coronavirus seems to differ from the SARS virus in some important ways ${ }^{3}$. Because the SARS virus binds to the ACE-2 receptor on human cells deep in the lungs, it causes serious disease in the lower respiratory tract but is relatively difficult to contract and is not easily spread by coughing or sneezing. The researchers have determined that the new coronavirus does not bind to the ACE-2 receptor, but declined to elaborate on which receptor it does use, pending a separate publication. But ruling out the ACE-2 receptor has immediate practical implications - all the reagents and therapeutic strategies developed for the SARS virus will be of little use with this latest virus, says Drosten.

The same team also found that cells from bats, pigs and humans can all be infected in the lab with the coronavirus. This suggests that it is "promiscuous among mammals", says Drosten, and that it might jump readily between mammal species, although he cautions against extrapolating such in vitro studies to the real world.

More clues have come from Ian Lipkin, a renowned 'virus hunter' from Columbia University in New York, who was invited by the Saudi government in October to study the first cases there. He told Nature that he has discovered that partial genetic sequences of a virus isolated from bats match the coronavirus found in humans. "The finding gives insight into the original source of the virus," he says.

The route taken by this coronavirus to infect humans is still not clear. It could, for example, be carried by intermediate animal hosts, or in foodstuffs contaminated by the faeces of bats or other infected animals. To answer that, says Lipkin, "one would need to work for months". He hopes to send in another team to work alongside his Saudi colleagues in the near future.

1. Corman, V. M. et al. Euro Surveill. 17, 39 (2012).

2. Corman, V. M. et al. Euro Surveill. 17, 49 (2012).

3. Müller, M. A. et al. mBio 3, e00515-12 (2012).

COMMUNITY

\section{NIH tackles major workforce issues}

\section{US agency aims to expand training options for graduate students and to increase demographic diversity.}

\section{BY MEREDITH WADMAN}

$\mathrm{T}$ The world's largest biomedical research funding agency last week announced a programme of nudges, incentives and requirements intended to respond to two thorny workforce-related problems: the oversupply of young scientists who face diminishing prospects of landing academic jobs, and the lack of demographic diversity in the US biomedical workforce.

Two reports issued in June challenged the US National Institutes of Health (NIH) to better prepare young biologists for an evolving and increasingly competitive job market, and to boost diversity (see Nature 486, 304; 2012). In response, the agency, based in Bethesda, Maryland, will spend an average of US $\$ 50$ million a year for 10 years on a grant programme designed to provide financial support and mentoring to undergraduates at less-researchintensive institutions, which tend to have more diverse student populations. Another set of up to 50 grants, each worth about $\$ 250,000$, will entice institutions to launch innovative training programmes that prepare students for careers outside academia, in everything from science policy to industry and research administration. The agency will also encourage universities and other institutions to limit NIH-supported doctoral studies to five years.

To measure the success of the new initiatives, the NIH will require universities and academic medical centres to track the careers of all of their NIH-funded graduate students and postdocs for 15 years after they are trained. "The challenges facing the biomedical workforce are complex and these proposed initiatives are designed to effect real change," says Francis Collins, director of the NIH. "I'm optimistic that the entire scientific-research community will come together to help implement them."

The National Medical Association (NMA) in Silver Spring, Maryland, the main group representing black medical scientists, praised the agency's diversity plans, which also include a nationwide mentoring consortium, training on diversity issues for NIH review staff and members of peer-review panels, and a pilot scheme to assess anonymized grant applications. These initiatives were spurred by a study showing that, when other factors such as education are controlled for, black applicants are 10\% less likely than whites to win NIH grant funding (D. K. Ginther et al. Science 333, 1015-1019; 2011). Rahn Bailey, president of the NMA, called the plans "a move in the right direction".

But Shirley Tilghman, who co-chaired the working group that wrote the June workforce report, said that simply encouraging institutions to limit the length of doctoral studies isn't enough. Tilgh-

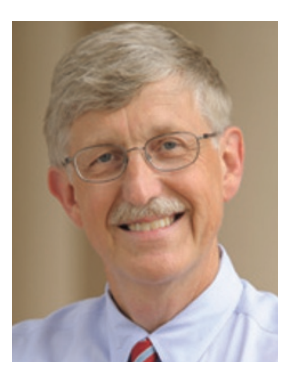

"These proposed initiatives are designed to effect real change." Francis Collins man, a molecular biologist and the president of Princeton University in New Jersey, told Collins's advisory committee on 6 December that "unless you get a stick, this won't happen". Her group's report noted that the number of US PhD biomedical graduates who secure tenure-track or tenured jobs has fallen from 34\% in 1993 to $26 \%$ today. She said that unless the NIH takes tougher steps, "we will be looking at data that look just like this ten more years from now".

Neither the June report nor the NIH response answer one key question - how many biomedical PhDs the United States should be training - because the necessary data and workforcemodelling expertise were not available either to the report's authors or to NIH staff. Indeed, the NIH also plans to hire at least one labour economist, to work as part of a new unit devoted to modelling biomedical-workforce needs.

As part of its workforce initiative, the NIH will increase yearly stipends for the 35,000 postdocs it supports from $\$ 39,000$ to $\$ 42,000$, a $7.7 \%$ rise, in an effort to reflect postdocs extensive training and to discourage lab heads from prolonging the postdoctoral training period. The National Postdoctoral Association in Washington DC applauded the NIH's plans. "The NIH has really stepped up to the plate in regard to early-career scientists," says Cathee Johnson Phillips, the group's executive director. The last time NIH-funded postdocs got a significant pay rise was in 2003 . 